Article

\title{
Conductive Hybrid Crystal Composed from Polyoxomolybdate and Deprotonatable Ionic-Liquid Surfactant
}

\author{
Jun Kobayashi ${ }^{1}$, Ryosuke Kawahara ${ }^{2}$, Sayaka Uchida ${ }^{2}$, Shinichi Koguchi ${ }^{1}$ and Takeru Ito ${ }^{1, *}$ \\ 1 Department of Chemistry, School of Science, Tokai University, 4-1-1 Kitakaname, Hiratsuka 259-1292, Japan; \\ j.koba92@gmail.com (J.K.); koguchi@tokai-u.jp (S.K.) \\ 2 Department of Basic Science, Graduate School of Arts and Sciences, The University of Tokyo, 3-8-1 Komaba, \\ Meguro-ku, Tokyo 153-8902, Japan; 9770832063@mail.ecc.u-tokyo.ac.jp (R.K.); \\ csayaka@mail.ecc.u-tokyo.ac.jp (S.U.) \\ * Correspondence: takeito@keyaki.cc.u-tokai.ac.jp; Tel.: +81-463-58-1211 (ext. 3737)
}

Academic Editors: Andreas Taubert and Peter Hesemann

Received: 11 April 2016; Accepted: 20 June 2016; Published: 23 June 2016

\begin{abstract}
A polyoxomolybdate inorganic-organic hybrid crystal was synthesized with deprotonatable ionic-liquid surfactant. 1-dodecylimidazolium cation was employed for its synthesis. The hybrid crystal contained $\delta$-type octamolybdate $\left(\mathrm{Mo}_{8}\right)$ isomer, and possessed alternate stacking of $\mathrm{Mo}_{8}$ monolayers and interdigitated surfactant bilayers. The crystal structure was compared with polyoxomolybdate hybrid crystals comprising 1-dodecyl-3-methylimidazolium surfactant, which preferred $\beta$-type $\mathrm{Mo}_{8}$ isomer. The less bulky hydrophilic moiety of the 1-dodecylimidazolium interacted with the $\delta-\mathrm{Mo}_{8}$ anion by $\mathrm{N}-\mathrm{H} \cdots \mathrm{O}$ hydrogen bonds, which presumably induced the formation of the $\delta-\mathrm{Mo}_{8}$ anion. Anhydrous conductivity of the hybrid crystal was estimated to be $5.5 \times 10^{-6} \mathrm{~S} \cdot \mathrm{cm}^{-1}$ at $443 \mathrm{~K}$ by alternating current (AC) impedance spectroscopy.
\end{abstract}

Keywords: inorganic-organic; hybrid crystal; polyoxometalate; ionic-liquid; surfactant

\section{Introduction}

Ionic-liquids exhibit characteristic conductive or catalytic properties, and enable us to construct functional hybrid materials [1-3]. Ionic-liquid species often contain imidazolium moiety in their molecular structures. Inorganic-organic materials comprising imidazolium ionic-liquid have been explored as ionic or proton conductors [4,5]. As for inorganic components in hybrid conducting materials, polyoxometalate anions are effective candidates [6-17]. Polyoxometalates and ionic-liquids have been successfully hybridized [18-22], and some of them exhibit promising conductive properties $[15,18]$.

In such polyoxometalate hybrids with ionic-liquids, the structure and arrangement of molecular components should be precisely controlled for the emergence of characteristic functions. To construct well-ordered polyoxometalate-ionic liquid hybrids, utilizing structure-directing species such as surfactant molecules [23-25] is advantageous. Polyoxometalate anions have been organized by surfactant cations to form inorganic-organic hybrids [26-40] and single crystals [41-57]. These polyoxometalate-surfactant hybrids allow flexible selection of the ionic components, which leads to precise engineering of the structure and function. In addition, polyoxometalate single crystals hybridized with ionic-liquid surfactants have also been reported [45,46,52-54].

We report here synthesis and structure of a polyoxomolybdate-ionic liquid hybrid crystal. Deprotonatable 1-dodecylimidazolium $\left(\left[\mathrm{C}_{3} \mathrm{H}_{4} \mathrm{~N}_{2}\left(\mathrm{C}_{12} \mathrm{H}_{25}\right)\right]^{+}\left(\mathrm{C}_{12} \mathrm{im}\right)\right.$, Figure 1a) cations were employed to obtain $\mathrm{C}_{12} \mathrm{im}$-polyoxomolybdate $\left(\mathrm{C}_{12} \mathrm{im}-\mathrm{Mo}\right)$ hybrids (referred to as $\mathbf{1}$ ). Recrystallization 
of $\mathrm{C}_{12} \mathrm{im}$-Mo hybrids resulted in the formation of single crystals comprising $\delta$-type isomer of octamolybdate $\left(\left[\mathrm{Mo}_{8} \mathrm{O}_{26}\right]^{4-}\left(\mathrm{Mo}_{8}\right)\right.$, Figure $\left.1 \mathrm{~b}\right)$ anion, $\mathrm{C}_{12} \mathrm{im}-\delta-\mathrm{Mo}_{8}$ (referred to as 2$)$. The weak interactions between $\mathrm{C}_{12}$ im cation and $\delta-\mathrm{Mo}_{8}$ anion were investigated, and anhydrous conductivity was estimated.

(a)

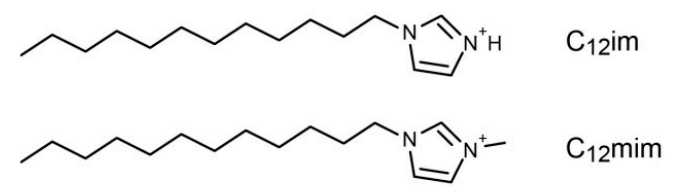

(b)
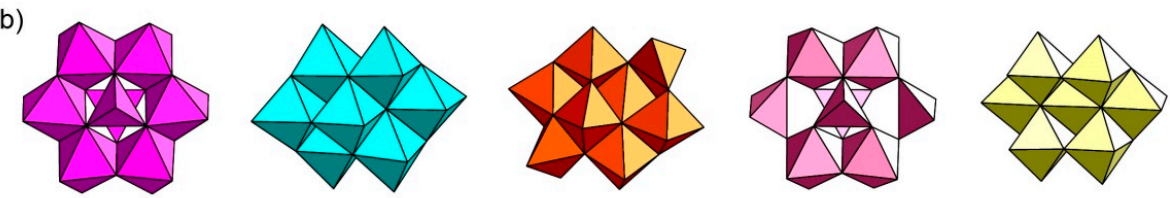

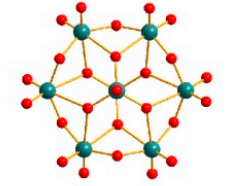

$\alpha-\mathrm{Mo}_{8}$

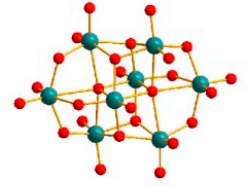

$\beta-M 08$

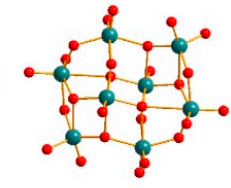

$\gamma-\mathrm{Mo8}$

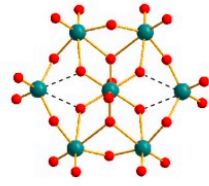

$\delta-\mathrm{Mo}_{8}$

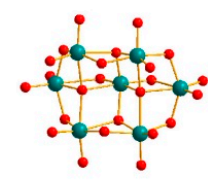

$\mathrm{Mo} 7$

Figure 1. Molecular structures of ionic-liquid surfactants and polyoxomolybdates: (a) 1-dodecylimidazolium $\left(\mathrm{C}_{12} \mathrm{im}\right)$ and 1-dodecyl-3-methylimidazolium $\left(\mathrm{C}_{12} \mathrm{mim}\right)$; (b) Octamolybdate $\left(\mathrm{Mo}_{8}\right)$ isomers and heptamolybdate $\left(\mathrm{Mo}_{7}\right)$ in ball and stick (green: $\mathrm{Mo}$, red: $\mathrm{O}$ ) and polyhedral representations.

\section{Results and Discussion}

\subsection{Syntheses of $\mathrm{C}_{12}$ im-Mo Hybrids}

As-prepared $\mathrm{C}_{12} \mathrm{im}-\mathrm{Mo}$ hybrids were obtained as insoluble precipitates from aqueous solution of sodium molybdate ( $\mathrm{pH}=3.6$ ) in $50 \%-65 \%$ yield (based on Mo). Figure 2 shows infrared (IR) spectra of as-prepared $\mathrm{C}_{12} \mathrm{im}$-Mo hybrids. The structure of the $\mathrm{C}_{12} \mathrm{im}$-Mo hybrids depended on the ionic-liquid species employed in the syntheses. Using neutral 1-dodecylimidazole $\left(\mathrm{C}_{3} \mathrm{H}_{3} \mathrm{~N}_{2}\left(\mathrm{C}_{12} \mathrm{H}_{25}\right)\right.$, denoted as $\mathrm{C}_{12} \mathrm{im}-\mathrm{N}$ ) as surfactant source resulted in the formation of $\mathrm{C}_{12} \mathrm{im}$-Mo hybrid of $\mathbf{1}$. The IR spectrum of 1 (Figure 2a) showed characteristic peaks in the range of $400-1000 \mathrm{~cm}^{-1}$, indicating conceivable presence of heptamolybdate $\left(\left[\mathrm{Mo}_{7} \mathrm{O}_{24}\right]^{6-}, \mathrm{Mo}_{7}\right)$ in the hybrid $[58,59]$. $\mathrm{C}_{12} \mathrm{im}-\mathrm{N}$ was acidified to form the $\mathrm{C}_{12} \mathrm{im}$ cation when added into the acidified sodium molybdate solution, and $\mathrm{pH}$ value will rise to cause the formation of the $\mathrm{Mo}_{7}$ anion [58,59]. On the other hand, utilizing the $\mathrm{C}_{12}$ im cation prepared by prior neutralization of $\mathrm{C}_{12} \mathrm{im}-\mathrm{N}$ with hydrochloric acid led to $\mathrm{C}_{12} \mathrm{im}$-Mo hybrid of 2 , which contained $\alpha$ - or $\delta$-type $\mathrm{Mo}_{8}$ anion (Figure $2 b$ ) $[47,58,59]$. The $\alpha$ - and $\delta$-type $\mathrm{Mo}_{8}$ isomers are difficult to distinguish only by IR spectra, since they have similar molecular structures except for some elongated Mo-O bonds of the $\delta-\mathrm{Mo}_{8}$ anion (represented in broken lines in Figure 1b). These $\mathrm{C}_{12} \mathrm{im}-\mathrm{Mo}$ hybrids of $\mathbf{1}$ and $\mathbf{2}$ exhibited distinct powder X-ray diffraction (XRD) patterns (Figure 3a,b), indicating the formation of pure crystalline compounds having different structures.

Recrystallization of both $\mathbf{1}$ and $\mathbf{2}$ enabled us to obtain single crystals, which were identified to possess the same molecular and crystal structure as 2, revealed by IR spectrum (Figure 2c) and powder XRD pattern (Figure 3c) of the single crystals. During the recrystallization process, the dissolved $\mathrm{Mo}_{7}$ anion from 1 will change to $\alpha$ - or $\delta-\mathrm{Mo}_{8}$ in the solution [59,60], which reprecipitated into the single crystals of 2 (Figures $2 a, c$ and $3 a, c)$. On the other hand, the structure of $\mathbf{2}$ was retained before and after the recrystallization process (Figures $2 \mathrm{~b}, \mathrm{c}$ and $3 \mathrm{~b}, \mathrm{c}$ ). Interestingly, the presence of $\mathrm{AlCl}_{3} \cdot 6 \mathrm{H}_{2} \mathrm{O}$ under the recrystallization process was necessary to obtain suitable single crystals, as in the case when 1-dodecyl-3-methylimidazolium cation $\left(\left[\left(\mathrm{C}_{12} \mathrm{H}_{25}\right) \mathrm{C}_{3} \mathrm{H}_{3} \mathrm{~N}_{2}\left(\mathrm{CH}_{3}\right)\right]^{+}, \mathrm{C}_{12} \mathrm{mim}\right)$ and $\beta$-type $\mathrm{Mo}_{8}$ anion were hybridized to form $\mathrm{C}_{12}$ mim- $\beta-\mathrm{Mo}_{8}$ (referred to as 3) [45]. No presence of $\mathrm{AlCl}_{3} \cdot 6 \mathrm{H}_{2} \mathrm{O}$ resulted in 
the formation of precipitates or crystals with worse quality. This implies that the hydrated $\mathrm{Al}^{3+}$ ion allows slow crystallization. In addition, the crystallization of $\mathbf{2}$ from $\mathbf{1}$ also requires the presence of $\mathrm{AlCl}_{3} \cdot 6 \mathrm{H}_{2} \mathrm{O}$, which may promote the structural conversion from $\mathrm{Mo}_{7}$ to $\alpha$ - or $\delta-\mathrm{Mo}_{8}$.

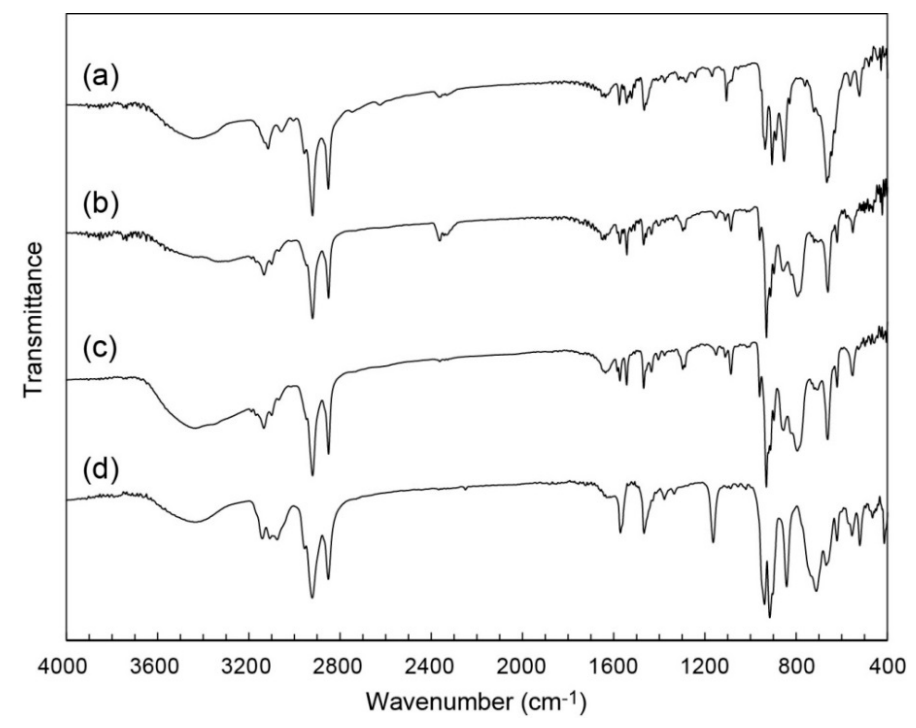

Figure 2. Infrared (IR) spectra of $\mathrm{C}_{12}$ im-Mo hybrids: (a) $\mathrm{C}_{12}$ im-Mo hybrid (1) obtained from $\mathrm{C}_{12} \mathrm{im}-\mathrm{N}$; (b) $\mathrm{C}_{12} \mathrm{im}-\delta-\mathrm{Mo}_{8}$ (2) obtained from $\mathrm{C}_{12} \mathrm{im} \cdot \mathrm{Cl}$; (c) 2 after recrystallization; (d) $\mathrm{C}_{12} \mathrm{mim}-\beta-\mathrm{Mo}_{8}$ (3) obtained by using $\mathrm{C}_{12} \mathrm{mim}$.

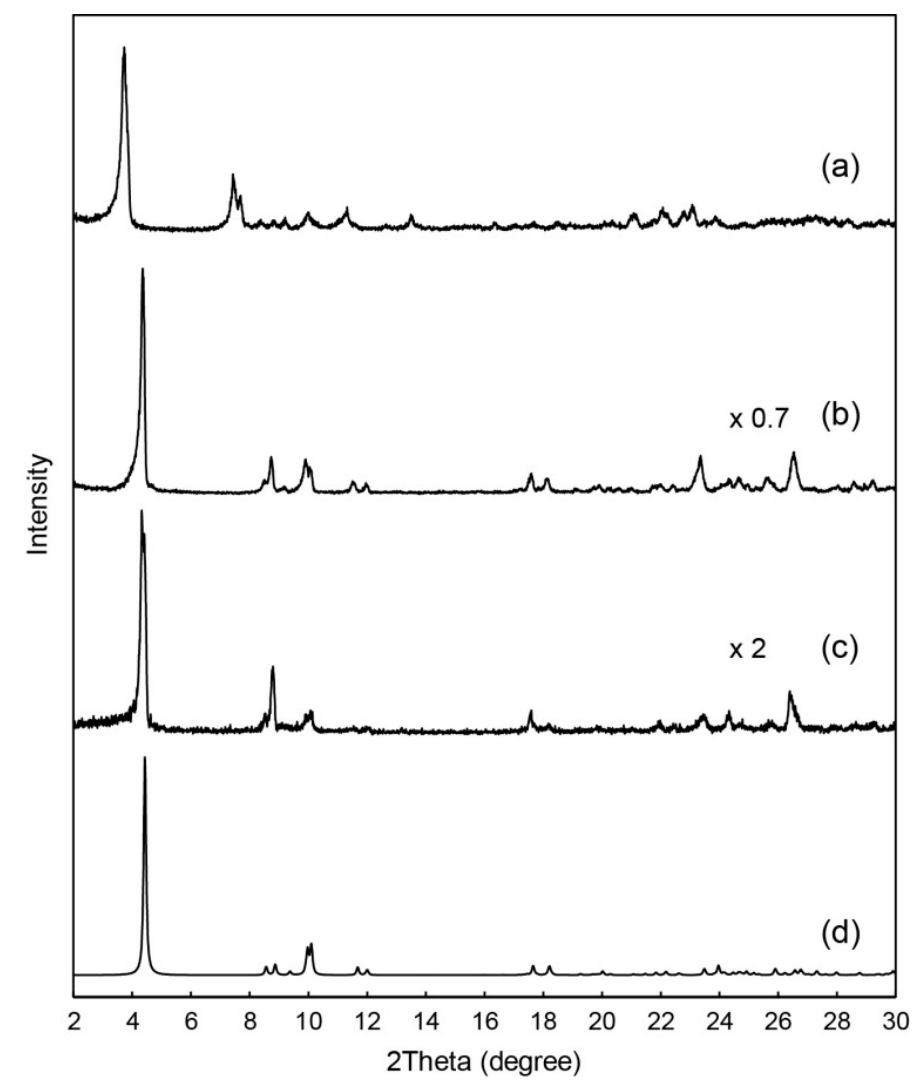

Figure 3. Powder $X$-ray diffraction (XRD) patterns of $\mathrm{C}_{12}$ im-Mo hybrids: (a) 1 obtained from $\mathrm{C}_{12}$ im-N; (b) 2 obtained from $\mathrm{C}_{12} \mathrm{im} \cdot \mathrm{Cl}$; (c) 2 after recrystallization; (d) Calculated pattern of 2 using the structure obtained by single-crystal XRD. 
The powder XRD patterns of as-prepared and recrystallized 2 measured at ambient temperature (Figure 3b,c) were almost the same in the peak position as the pattern calculated from the results of single crystal X-ray analysis (Figure 3d). This indicates that $\mathbf{2}$ was obtained as a single phase, being consistent with the results of elemental analyses. Slight differences in the peak intensity and position of the patterns may be due to the difference in the measurement temperature (powder: ambient temperature, single crystal: $93 \mathrm{~K}$ ), and to preferred orientation derived from the predominant layered structure of 2.

\subsection{Crystal Structure of $\mathrm{C}_{12}$ im- $\delta-\mathrm{Mo}_{8}$ (2)}

The X-ray structure and elemental analyses revealed the formula of 2 to be $\left[\mathrm{C}_{3} \mathrm{H}_{4} \mathrm{~N}_{2}\left(\mathrm{C}_{12} \mathrm{H}_{25}\right)\right]_{4}\left[\delta-\mathrm{Mo}_{8} \mathrm{O}_{26}\right]$ (Table 1). The crystal structure contained $\delta$-type $\mathrm{Mo}_{8}$ anion with no solvent of crystallization, which was consistent with the IR spectrum (Figure $2 \mathrm{c}$ ). Four $\mathrm{C}_{12}$ im cations (1+ charge) were associated with one $\delta-\mathrm{Mo}_{8}$ anion (4-charge) due to the charge compensation. 2 contained only the $\mathrm{C}_{12}$ im cation as counter cation, being similar to the hybrid crystal of 3 [45].

Table 1. Crystallographic data.

\begin{tabular}{|c|c|}
\hline Compound & $\mathrm{C}_{12} \mathrm{im}-\delta-\mathrm{Mo}_{8}(2)$ \\
\hline Chemical formula & $\mathrm{C}_{60} \mathrm{H}_{116} \mathrm{~N}_{8} \mathrm{Mo}_{8} \mathrm{O}_{26}$ \\
\hline Formula weight & 2133.13 \\
\hline Crystal system & monoclinic \\
\hline Space group & $P 2_{1} / c$ (No. 14$)$ \\
\hline$a(\AA)$ & $21.859(4)$ \\
\hline$b(\AA)$ & $10.0395(18)$ \\
\hline$c(\AA)$ & $20.683(4)$ \\
\hline$\alpha\left({ }^{\circ}\right)$ & 90.0000 \\
\hline$\beta\left({ }^{\circ}\right)$ & $114.307(2)$ \\
\hline$\gamma\left({ }^{\circ}\right)$ & 90.0000 \\
\hline$V\left(\AA^{3}\right)$ & $4136.7(14)$ \\
\hline$Z$ & 2 \\
\hline$\rho_{\text {calcd }}\left(\mathrm{g} \cdot \mathrm{cm}^{-3}\right)$ & 1.712 \\
\hline$T(\mathrm{~K})$ & 93 \\
\hline$\mu(\mathrm{Mo} \cdot \mathrm{K} \alpha)\left(\mathrm{mm}^{-1}\right)$ & 1.244 \\
\hline No. of reflections measured & 27938 \\
\hline No. of independent reflections & 7550 \\
\hline$R_{\text {int }}$ & 0.0463 \\
\hline No. of parameters & 460 \\
\hline$R_{1}(I>2 \sigma(I))$ & 0.0422 \\
\hline$w R_{2}$ (all data) & 0.1292 \\
\hline
\end{tabular}

The IR spectra of 2 exhibited the characteristic peaks of $\delta-\mathrm{Mo}_{8}$ (Figure $2 \mathrm{~b}, \mathrm{c}$ ), which contrasted with that of 3, which consists of the $\beta-\mathrm{Mo}_{8}$ anion (Figure 2d). This difference in the $\mathrm{Mo}_{8}$ isomer structures is notable, since $\mathrm{C}_{12}$ mim cation preferred $\beta$ - or $\gamma$-type $\mathrm{Mo}_{8}$ anion $[45,46]$. The difference in the $\mathrm{Mo}_{8}$ isomers seems to depend on the difference in the hydrophilic moiety of ionic-liquid surfactants. $\mathrm{C}_{12} \mathrm{im}$ has no methyl group in the imidazole ring, while $\mathrm{C}_{12}$ mim has one methyl group. The charged imidazolium moiety of $\mathrm{C}_{12} \mathrm{im}$ or $\mathrm{C}_{12}$ mim strongly interacts with $\mathrm{Mo}_{8}$ anions. The difference in the bulkiness of the hydrophilic moiety and in the ability to form a strong $\mathrm{N}-\mathrm{H} \cdots$ O hydrogen bond (see below) may result in the formation of different $\mathrm{Mo}_{8}$ isomer structures in $\mathbf{2}$ and $\mathbf{3}$.

Figure 4 shows the crystal structure of 2 . The crystal packing consisted of alternating $\delta \mathrm{Mo}_{8}$ inorganic monolayers and $C_{12}$ im organic bilayers with an interlayer distance of $19.9 \AA$ (Figure $4 a, b$ ). The hydrophilic heads of $\mathrm{C}_{12}$ im penetrated into the $\delta-\mathrm{Mo}_{8}$ layers to isolate each $\delta-\mathrm{Mo}_{8}$ anion (Figure $4 \mathrm{c}$ ), being similar to that in the crystal of 3 [45]. The two crystallographically independent $C_{12}$ im cations formed a paired structure (Figure 5). They had a slight overlap of the imidazole rings, indicating the presence of a $\pi-\pi$ stacking interaction (distance of $\mathrm{C} 2-\mathrm{C} 17$ bond between the imidazole rings: $3.38 \AA$ ). 
All $\mathrm{C}-\mathrm{C}$ bonds of the $\mathrm{C}_{12} \mathrm{im}$ in 2 had anti conformation. These conformations of the imidazole rings and long alkyl chain were similar to the crystal of 3 [45].

(a)

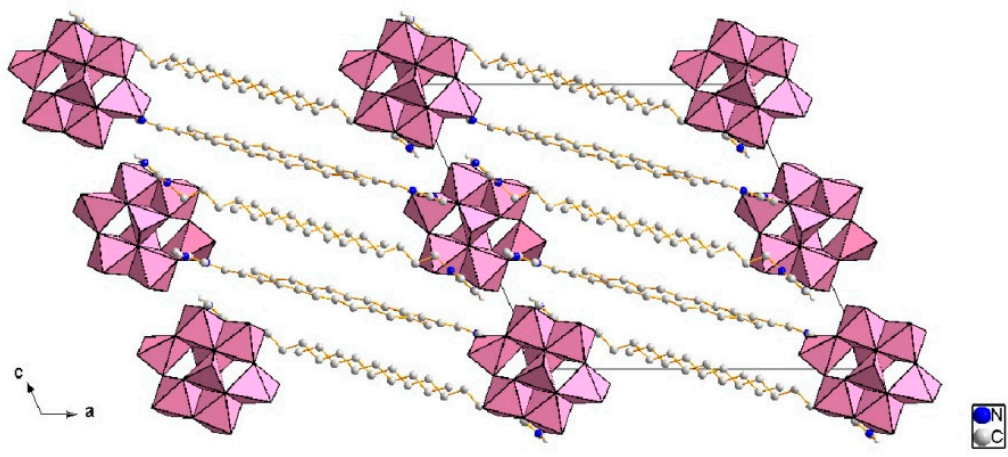

(b)

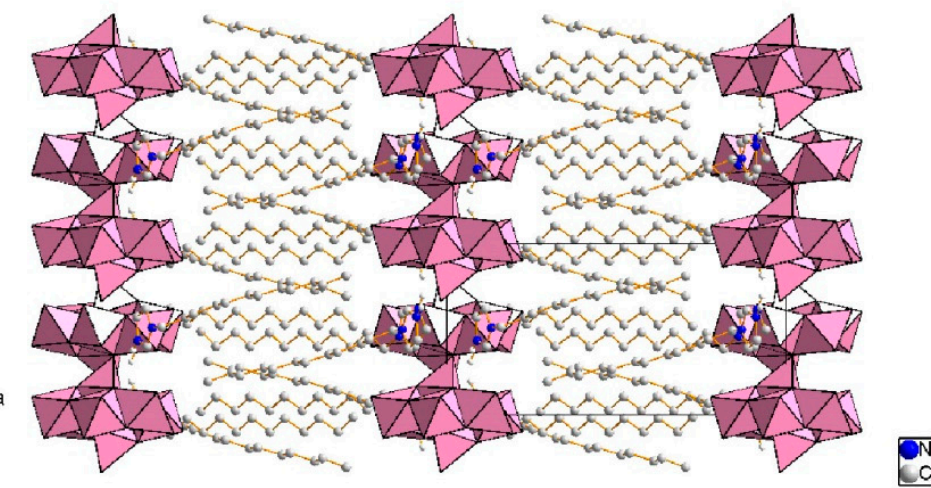

(c)

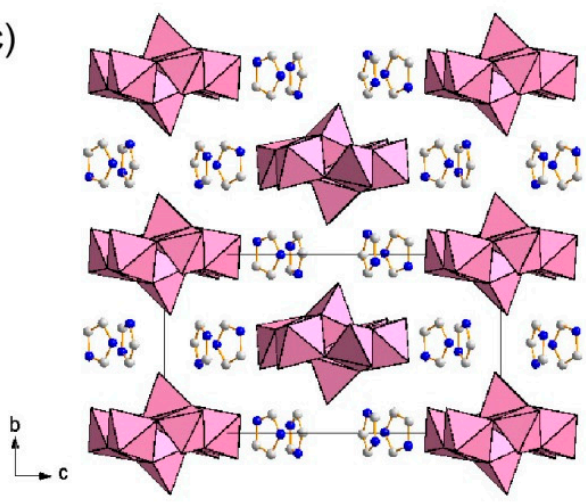

Figure 4. Crystal structure of 2 (C: gray, $\mathrm{N}$ : blue; $\delta-\mathrm{Mo}_{8}$ anions in polyhedral representations). $\mathrm{H}$ atoms are omitted for clarity; (a) Packing diagram along $b$ axis; (b) Packing diagram along $c$ axis; (c) Molecular arrangements in the inorganic layers. The dodecyl groups are omitted for clarity.

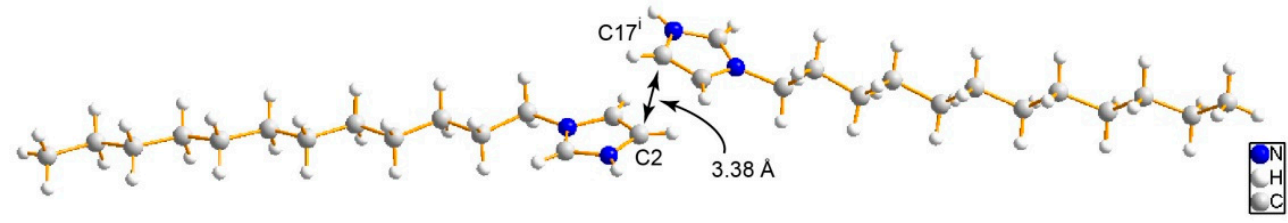

Figure 5. View of crystallographically independent $C_{12}$ im cations. Symmetry code: $(i)-x,-0.5+y$, $0.5-z$.

In the crystal structure of 2, two types of hydrogen bond were observed, namely $\mathrm{N}-\mathrm{H} \cdots \mathrm{O}$ and $\mathrm{C}-\mathrm{H} \cdots \mathrm{O}$ hydrogen bonds [61]. Most hydrogen bonds were formed at the interface between the $\delta-\mathrm{Mo}_{8}$ and $\mathrm{C}_{12}$ im layers. The $\mathrm{N}-\mathrm{H} \cdots \mathrm{O}$ hydrogen bonds were derived from protonated nitrogen atom of 
imidazole ring in the $\mathrm{C}_{12} \mathrm{im}$ cation. The $\mathrm{N} \cdots \mathrm{O}$ distances of the $\mathrm{N}-\mathrm{H} \cdots \mathrm{O}$ hydrogen bond in 2 were 2.89-3.09 $\AA$ (mean value: $2.97 \AA$ ), indicating the presence of strong hydrogen bonds. The $\mathrm{C}-\mathrm{H} \cdots \mathrm{O}$ hydrogen bond in 2 exhibited C . . O distances of 2.87-3.86 $\AA$ (mean value: $3.42 \AA$ ), which was similar to the C... O distances in $3(3.04-3.85 \AA$, mean value: $3.42 \AA)$ [45,62].

\subsection{Conductivity of $\mathrm{C}_{12}$ im- $\delta-M o_{8}$ (2)}

Figure 6 shows an impedance spectrum for as-prepared 2 at $443 \mathrm{~K}$ under anhydrous atmosphere. As mentioned above, 2 retained both molecular and crystal structures before and after the recrystallization process. The spectrum showed a suppressed half circle in the high- and medium-frequency regions and an inclined line in the low-frequency region. The suppressed half circle will be derived from two overlapped semicircles due to bulk and grain boundary elements [48,49]. The linear part in the low-frequency region would result from combination of charge transfer resistance and Warburg impedance related to the diffusion of the carrier. The equivalent circuit employed here is shown in Figure 6 (inset). It consists of bulk resistance and capacitance $\left(R_{\mathrm{b}}\right.$ and $\left.C_{\mathrm{b}}\right)$, grain boundary resistance and capacitance $\left(R_{\mathrm{gb}}\right.$ and $\left.C_{\mathrm{gb}}\right)$, and charge transfer resistance $\left(R_{\mathrm{ct}}\right)$ along with double layer capacitance $\left(C_{\mathrm{dl}}\right) . Z_{\mathrm{W}}$ represents the Warburg impedance. The red line in Figure 6 represents simulated data with the equivalent circuit, which successfully reproduced the measured impedance spectrum. The estimated value of $R_{\mathrm{b}}$ was $1.85 \times 10^{4} \Omega$, from which the conductivity of 2 was calculated to be $5.5 \times 10^{-6} \mathrm{~S} \cdot \mathrm{cm}^{-1}$. This anhydrous conductivity is due to the residual proton in the bulk solid of 2 derived from the deprotonatable $\mathrm{C}_{12} \mathrm{im}$ cation, since 2 contained no molecule of crystallization nor small counter cation as a plausible source of carrier. The proton attached to the imidazole ring in $\mathrm{C}_{12} \mathrm{im}$ will be dissociated at the intermediate temperature of $443 \mathrm{~K}$. Although the value of the anhydrous conductivity is not high enough, conductive polyoxometalate-surfactant hybrid crystals would pave a way to another class of anhydrous proton conductors at intermediate temperatures.

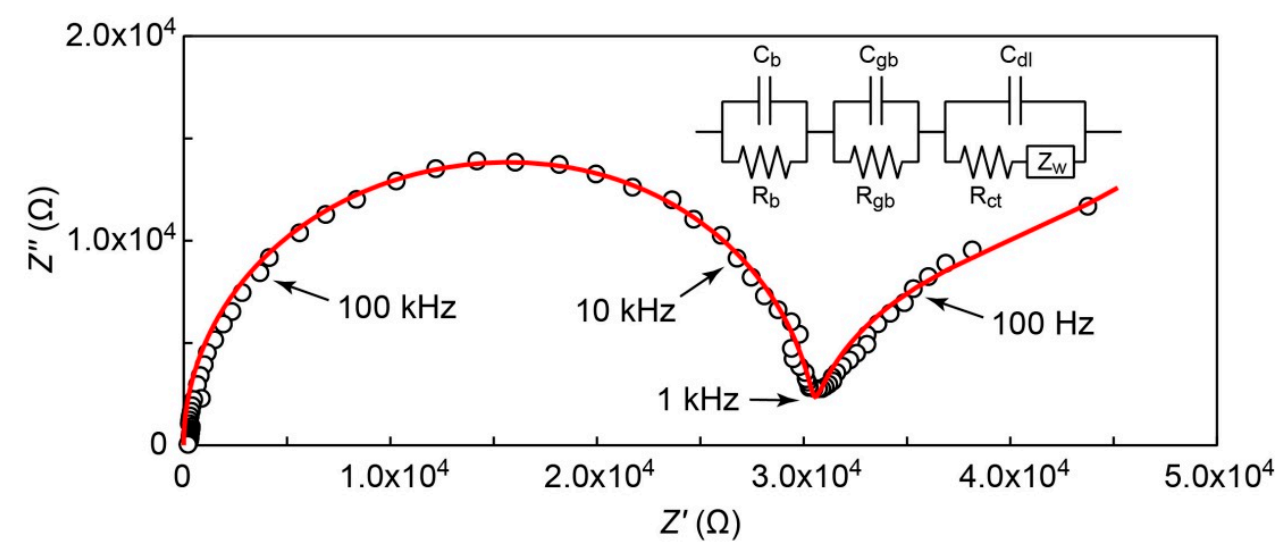

Figure 6. Nyquist spectrum (open circles) of as-prepared $\mathrm{C}_{12} \mathrm{im}-\delta-\mathrm{Mo}_{8}(2)$ at $443 \mathrm{~K}$ and simulated spectrum (red line) based on an equivalent electronic circuit in the figure. The parameters obtained by the fitting (see text) are as follows: $R_{\mathrm{b}}=1.85 \times 10^{4} \Omega, R_{\mathrm{gb}}=1.2 \times 10^{4} \Omega, R_{\mathrm{ct}}=1.1 \times 10^{4} \Omega$, $C_{\mathrm{b}}=1.0 \times 10^{-8} \mathrm{~F}, C_{\mathrm{gb}}=6.0 \times 10^{-9} \mathrm{~F}, C_{\mathrm{dl}}=3.0 \times 10^{-6} \mathrm{~F}, \sigma=2.2 \times 10^{4} \Omega \cdot \mathrm{s}^{-1 / 2}\left(Z_{\mathrm{w}}=(1-j) \sigma / \sqrt{\omega}\right)$.

\section{Materials and Methods}

\subsection{Materials and Genaral Methods}

All chemical reagents except for imidazolium surfactant were obtained from commercial sources (Wako, Osaka, Japan and TCI, Tokyo, Japan, the highest grade). 1-dodecylimidazole $\left(\mathrm{C}_{12} \mathrm{im}-\mathrm{N}\right)$ and its hydrochloric-acid salt $\left(\left[\mathrm{C}_{3} \mathrm{H}_{4} \mathrm{~N}_{2}\left(\mathrm{C}_{12} \mathrm{H}_{25}\right)\right] \mathrm{Cl}, \mathrm{C}_{12} \mathrm{im} \cdot \mathrm{Cl}\right)$ were prepared according to the literature [63]. 
IR spectra (as KBr pellet) were recorded on a Jasco FT/IR-4200ST spectrometer (Tokyo, Japan). Powder X-ray diffraction (XRD) patterns were measured with a Rigaku MiniFlex300 diffractometer by using $\mathrm{Cu} \mathrm{K} \alpha$ radiation $(\lambda=1.54056 \AA)$ at ambient temperature.

Conductivity measurements were carried out by alternating current (AC) impedance method in a frequency range from 20 to $1.0 \times 10^{7} \mathrm{~Hz}$ using a Wayne Kerr 6510P inductance-capacitance-resistance (LCR) meter. Pelletized powder samples (10 $\mathrm{mm}$ in diameter, $0.79 \mathrm{~mm}$ in thickness) were sandwiched with Pt electrodes, and the impedance was measured under a dry $\mathrm{N}_{2}$ atmosphere at $443 \mathrm{~K}$.

\subsection{Synthesis}

As-prepared $\mathrm{C}_{12} \mathrm{im}-\mathrm{Mo}$ hybrid of 1 was precipitated by adding ethanol solution of $\mathrm{C}_{12} \mathrm{im}-\mathrm{N}$ $(0.2 \mathrm{M}, 10 \mathrm{~mL})$ to $\mathrm{Na}_{2} \mathrm{MoO}_{4} \cdot 2 \mathrm{H}_{2} \mathrm{O}$ aqueous solution $(0.4 \mathrm{M}, 10 \mathrm{~mL})$, which was adjusted to $\mathrm{pH} 3.6$ with $6 \mathrm{M} \mathrm{HCl}$. The precipitates were isolated by filtration, and dried in the ambient atmosphere to obtain colorless powder of 1 in a yield of $64 \%$. Melting point: $463 \mathrm{~K}$. IR (KBr disk): $936(\mathrm{~m}), 905(\mathrm{~s}), 889(\mathrm{~m})$, $853(\mathrm{~s}), 829(\mathrm{w}), 761(\mathrm{w}), 722(\mathrm{w}), 665(\mathrm{vs}), 644(\mathrm{~m}), 563(\mathrm{w}), 523(\mathrm{w}), 481(\mathrm{w}), 444(\mathrm{w}), 428(\mathrm{w}) \mathrm{cm}^{-1}$.

$\mathrm{C}_{12} \mathrm{im}-\delta-\mathrm{Mo}_{8}$ hybrid of 2 was prepared as follows: to aqueous solution of $\mathrm{Na}_{2} \mathrm{MoO}_{4} \cdot 2 \mathrm{H}_{2} \mathrm{O}$ $(0.4 \mathrm{M}, 10 \mathrm{~mL})$ acidified to $\mathrm{pH} 3.6$ with $6 \mathrm{M} \mathrm{HCl}$ was added ethanol solution of $\mathrm{C}_{12} \mathrm{im}-\mathrm{N}(0.2 \mathrm{M}, 10 \mathrm{~mL})$ neutralized by $1 \mathrm{M} \mathrm{HCl}(1.7 \mathrm{~mL})$. The resulting precipitates were isolated by filtration, and dried in the ambient atmosphere to obtain colorless powder of $\mathbf{2}$ in a yield of $59 \%$. Using ethanol solution of $\mathrm{C}_{12} \mathrm{im} \cdot \mathrm{Cl}(0.2 \mathrm{M}, 10 \mathrm{~mL})$ instead of the acidified $\mathrm{C}_{12} \mathrm{im}-\mathrm{N}$ solution gave the same hybrids (yield: $52 \%$ ). Anal.: Calcd for $\mathrm{C}_{60} \mathrm{H}_{116} \mathrm{~N}_{8} \mathrm{Mo}_{8} \mathrm{O}_{26}$ : C: $33.78, \mathrm{H}: 5.48, \mathrm{~N}: 5.25 \%$. Found: C: 33.14, H: 5.21, N: $5.11 \%$. Melting point: $501 \mathrm{~K}$. IR (KBr disk): 960 (w), 930 (s), 912 (s), 898 (m), 856 (m), 795 (s), 721 (w), 661 (s), $620(\mathrm{w}), 552(\mathrm{w}), 499(\mathrm{w}), 464(\mathrm{w}), 422(\mathrm{w}) \mathrm{cm}^{-1}$.

Colorless platelet crystals of 2 were obtained as follows: acetonitrile solution $(15 \mathrm{~mL})$ of the as-prepared $\mathrm{C}_{12} \mathrm{im}$-Mo hybrid (1 or 2, $\left.0.03 \mathrm{~g}\right)$ and $\mathrm{AlCl}_{3} \cdot 6 \mathrm{H}_{2} \mathrm{O}(0.02 \mathrm{~g})$ was kept at $323 \mathrm{~K}$ for one day. The resulting supernatant was kept at $303 \mathrm{~K}$ for a few days, and then evaporated at room temperature to obtain colorless plates of 2 in ca. $30 \%$ yield. Anal.: Calcd for $\mathrm{C}_{60} \mathrm{H}_{116} \mathrm{~N}_{8} \mathrm{Mo}_{8} \mathrm{O}_{26}$ : C: $33.78, \mathrm{H}: 5.48, \mathrm{~N}$ : 5.25\%. Found: C: 34.49, H: 5.66, N: 5.30\%. Melting point: 493 K. IR (KBr disk): 960 (w), 930 (s), 912 (s), $898(\mathrm{~m}), 855(\mathrm{~m}), 795(\mathrm{~s}), 707(\mathrm{w}), 661(\mathrm{~s}), 620(\mathrm{w}), 553(\mathrm{w}), 498(\mathrm{w}), 472(\mathrm{w}), 457(\mathrm{w}) \mathrm{cm}^{-1}$.

\subsection{X-ray Crystallography}

Single crystal XRD measurements were performed on a Rigaku Saturn70 diffractometer (Tokyo, Japan) using graphite monochromated Mo-K $\alpha$ radiation $(\lambda=0.71075 \AA)$. Diffraction data were collected and processed with CrystalClear [64]. The structure was solved by direct methods [65]. The refinement procedure was performed by the full-matrix least-squares using SHELXL Version 2014/7 [66]. All calculations were performed using the CrystalStructure [67] software package. All non-hydrogen atoms were refined anisotropically, and the hydrogen atoms on $\mathrm{C}$ atoms were refined using the riding model. Further details of the crystal structure investigation may be obtained free of charge from the Cambridge Crystallographic Data Centre, 12 Union Road, Cambridge CB2 1EZ, UK; fax: (+44)-1223-336-033; or E-Mail: deposit@ccdc.cam.ac.uk (CCDC 1472277).

\section{Conclusions}

Polyoxomolybdate hybrid crystals were successfully obtained by employing deprotonatable ionic-liquid cation, 1-dodecylimidazolium $\left(\left[\mathrm{C}_{3} \mathrm{H}_{4} \mathrm{~N}_{2}\left(\mathrm{C}_{12} \mathrm{H}_{25}\right)\right]^{+}, \mathrm{C}_{12} \mathrm{im}\right)$. The crystal contained $\delta$-type octamolybdate $\left(\left[\mathrm{Mo}_{8} \mathrm{O}_{26}\right]^{4-}, \mathrm{Mo}_{8}\right)$, being different from the case of crystals comprising methylimidazolium surfactant having no dissociative proton. The crystal structure of $\mathrm{C}_{12} \mathrm{im}-\delta-\mathrm{Mo}_{8}$ consisted of alternate stacking of the $\delta$-Mos layers and $\mathrm{C}_{12}$ im layers. The hydrophilic moiety of the $\mathrm{C}_{12}$ im cation formed $\mathrm{N}-\mathrm{H} \cdots \mathrm{O}$ and $\mathrm{C}-\mathrm{H} \cdots \mathrm{O}$ hydrogen bonds between the Mog anions, and the presence of the $\mathrm{N}-\mathrm{H} \cdots \mathrm{O}$ hydrogen bonds suggests the formation $\delta$-type $\mathrm{Mo}_{8}$ in the $\mathrm{C}_{12} \mathrm{im}-\delta$-Mo crystal. The $\mathrm{C}_{12} \mathrm{im}-\delta-\mathrm{Mo}_{8}$ crystal exhibited anhydrous conductivity of $5.5 \times 10^{-6} \mathrm{~S} \cdot \mathrm{cm}^{-1}$ at $443 \mathrm{~K}$ 
presumably due to the proton dissociated from the protonated $\mathrm{C}_{12} \mathrm{im}$ cation, which is promising for the exploration of anhydrous proton conductors working at an intermediate temperature region.

Supplementary Materials: Supplementary materials can be found at http://www.mdpi.com/1422-0067/17/ 7/994/s1, cif file of $\mathrm{C}_{12} \mathrm{im}-\delta-\mathrm{Mo}_{8}(2)$.

Acknowledgments: This work was supported in part by JSPS Grant-in-Aid for Scientific Research (No. 26410245), and Research and Study Project of Tokai University Educational System General Research Organization.

Author Contributions: Jun Kobayashi and Takeru Ito conceived and designed the experiments; Jun Kobayashi performed the experiments; Jun Kobayashi and Takeru Ito analyzed the data; Ryosuke Kawahara and Sayaka Uchida contributed analysis tools and discussions on the results; Shinichi Koguchi contributed materials; Takeru Ito wrote the paper.

Conflicts of Interest: The authors declare no conflict of interest.

\section{References and Notes}

1. Welton, T. Room-temperature ionic liquids. Solvents for synthesis and catalysis. Chem. Rev. 1999, 99, 2071-2083. [CrossRef] [PubMed]

2. Wasserscheid, P.; Keim, W. Ionic liquids-new "solutions" for transition metal catalysis. Angew. Chem. Int. Ed. 2000, 39, 3772-3789. [CrossRef]

3. Haumann, M.; Riisager, A. Hydroformylation in room temperature ionic liquids (RTILs): Catalyst and process developments. Chem. Rev. 2008, 108, 1474-1497. [CrossRef] [PubMed]

4. Kato, T.; Mizoshita, M.; Kishimoto, K. Functional liquid-crystalline assemblies: Self-organized soft materials. Angew. Chem. Int. Ed. 2006, 45, 38-68. [CrossRef] [PubMed]

5. Bureekaew, S.; Horike, S.; Higuchi, H.; Mizuno, M.; Kawamura, T.; Tanaka, D.; Yanai, N.; Kitagawa, S. One-dimensional imidazole aggregate in aluminium porous coordination polymers with high proton conductivity. Nat. Mater. 2009, 8, 831-836. [CrossRef] [PubMed]

6. Long, D.-L.; Burkholder, E.; Cronin, L. Polyoxometalate clusters, nanostructures and materials: From self assembly to designer materials and devices. Chem. Soc. Rev. 2007, 36, 105-121. [CrossRef] [PubMed]

7. Nyman, M. Polyoxoniobate chemistry in the 21st century. Dalton Trans. 2011, 40, 8049-8058. [CrossRef] [PubMed]

8. Proust, A.; Matt, B.; Villanneau, R.; Guillemot, G.; Gouzerh, P.; Izzet, G. Functionalization and post-functionalization: A step towards polyoxometalate-based materials. Chem. Soc. Rev. 2012, 41, 7605-7622. [CrossRef] [PubMed]

9. Okuhara, T.; Mizuno, N.; Misono, M. Catalytic chemistry of heteropoly compounds. Adv. Catal. 1996, 41, 113-252.

10. Yamase, T. Photo- and electrochromism of polyoxometalates and related materials. Chem. Rev. 1998, 98, 307-325. [CrossRef] [PubMed]

11. Sadakane, M.; Steckhan, E. Electrochemical properties of polyoxometalates as electrocatalysts. Chem. Rev. 1998, 98, 219-237. [CrossRef] [PubMed]

12. Coronado, E.; Gómez-García, C.J. Polyoxometalate-based molecular materials. Chem. Rev. 1998, 98, $273-296$. [CrossRef] [PubMed]

13. Coronado, E.; Giménez-Saiz, C.; Gómez-García, C.J. Recent advances in polyoxometalate-containing molecular conductors. Coord. Chem. Rev. 2005, 249, 1776-1796. [CrossRef]

14. Nakamura, O.; Kodama, T.; Ogino, I.; Miyake, Y. High-conductivity solid proton conductors: Dodecamolybdophosphoric acid and dodecatungstophosphoric acid crystals. Chem. Lett. 1979, 8, 17-18. [CrossRef]

15. Honma, I.; Yamada, M. Bio-inspired membranes for advanced polymer electrolyte fuel cells. Anhydrous proton-conducting membrane via molecular self-assembly. Bull. Chem. Soc. Jpn. 2007, 80, 2110-2123. [CrossRef]

16. Oh, S.-Y.; Yoshida, T.; Kawamura, G.; Muto, H.; Sakai, M.; Matsuda, A. Inorganic-organic composite electrolytes consisting of polybenzimidazole and Cs-substituted heteropoly acids and their application for medium temperature fuel cells. J. Mater. Chem. 2010, 20, 6359-6366. [CrossRef] 
17. Tsuboi, M.; Hibino, M.; Mizuno, N.; Uchida, S. Crystalline polyoxometalate (POM)-polyethylene glycol (PEG) composites aimed as non-humidified intermediate-temperature proton conductors. J. Solid State Chem. 2016, 234, 9-14. [CrossRef]

18. Bourlinos, A.B.; Raman, K.; Herrera, R.; Zhang, Q.; Archer, L.A.; Giannelis, E.P. A liquid derivative of 12-tungstophosphoric acid with unusually high conductivity. J. Am. Chem. Soc. 2004, 126, 15358-15359. [CrossRef] [PubMed]

19. Leng, Y.; Wang, J.; Zhu, D.; Ren, X.; Ge, H.; Shen, L. Heteropolyanion-based ionic liquids: Reaction-induced self-separation catalysts for esterification. Angew. Chem. Int. Ed. 2009, 48, 168-171. [CrossRef] [PubMed]

20. Rafiee, E.; Evani, S. Polyoxometalate-based acid salts with tunable separation properties as recyclable Brönsted acid catalysts for the synthesis of $\beta$-keto enol ethers. Catal. Commun. 2012, 25, 64-68. [CrossRef]

21. Chen, X.; Souvanhthong, B.; Wang, H.; Zheng, H.; Wang, X.; Huo, M. Polyoxometalate-based ionic liquid as thermoregulated and environmentally friendly catalyst for starch oxidation. Appl. Catal. B 2013, 138-139, 161-166. [CrossRef]

22. Rickert, P.G.; Antonio, M.R.; Firestone, M.A.; Kubatko, K.-A.; Szreder, T.; James, F.; Wishart, J.F.; Dietz, M.L. Tetraalkylphosphonium polyoxometalate ionic liquids: Novel, organic-inorganic hybrid materials. J. Phys. Chem. B 2007, 111, 4685-4692. [CrossRef] [PubMed]

23. Huo, Q.; Margolese, D.I.; Ciesla, U.; Demuth, D.G.; Feng, P.; Gier, T.E.; Sieger, P.; Firouzi, A.; Chmelka, B.F. Organization of organic molecules with inorganic molecular species into nanocomposite biphase arrays. Chem. Mater. 1994, 6, 1176-1191. [CrossRef]

24. Kanatzidis, M.G. Beyond silica: Nonoxidic mesostructured materials. Adv. Mater. 2007, 19, $1165-1181$. [CrossRef]

25. Yamauchi, Y.; Kuroda, K. Rational design of mesoporous metals and related nanomaterials by a soft-template approach. Chem. Asian J. 2008, 3, 664-676. [CrossRef] [PubMed]

26. Song, Y.-F.; Long, D.-L.; Ritchie, C.; Cronin, L. Nanoscale polyoxometalate-based inorganic/organic hybrids. Chem. Rec. 2011, 11, 158-171. [CrossRef] [PubMed]

27. Yin, P.; Li, D.; Liu, T. Solution behaviors and self-assembly of polyoxometalates as models of macroions and amphiphilic polyoxometalate-organic hybrids as novel surfactants. Chem. Soc. Rev. 2012, 41, 7368-7383. [CrossRef] [PubMed]

28. Polarz, S.; Landsmann, S.; Klaiber, A. Hybrid surfactant systems with inorganic constituents. Angew. Chem. Int. Ed. 2014, 53, 946-954. [CrossRef] [PubMed]

29. Clemente-León, M.; Coronado, E.; Soriano-Portillo, A.; Mingotaud, C.; Dominguez-Vera, J.M. Langmuir-Blodgett films based on inorganic molecular complexes with magnetic or optical properties? Adv. Colloid Interface Sci. 2005, 116, 193-203. [CrossRef] [PubMed]

30. Nisar, A.; Wang, X. Surfactant-encapsulated polyoxometalate building blocks: Controlled assembly and their catalytic properties. Dalton Trans. 2012, 41, 9832-9845. [CrossRef] [PubMed]

31. Zhang, T.; Liu, S.; Kurth, D.G.; Faul, C.F.J. Organized nanostructured complexes of polyoxometalates and surfactants that exhibit photoluminescence and electrochromism. Adv. Funct. Mater. 2009, 19, 642-652. [CrossRef]

32. Qi, W.; Wu, L. Polyoxometalate/polymer hybrid materials: Fabrication and properties. Polym. Int. 2009, 58, 1217-1225. [CrossRef]

33. Ito, T. Polyoxometalate-surfactant hybrids as building strategy for two-dimensional molecular arrays. Polyoxometalate Chem. 2012, 1, 6-14.

34. Stein, A.; Fendorf, M.; Jarvie, T.P.; Mueller, K.T.; Benesi, A.J.; Mallouk, T.E. Salt-gel synthesis of porous transition-metal oxides. Chem. Mater. 1995, 7, 304-313. [CrossRef]

35. Janauer, G.G.; Dobley, A.; Guo, J.; Zavalij, P.; Whittingham, M.S. Novel tungsten, molybdenum, and vanadium oxides containing surfactant ions. Chem. Mater. 1996, 8, 2096-2101. [CrossRef]

36. Taguchi, A.; Abe, T.; Iwamoto, M. Non-silica-based mesostructured materials: Hexagonally mesostructured array of surfactant micelles and 11-tungstophosphoric heteropoly anions. Adv. Mater. 1998, 10, 667-669. [CrossRef]

37. Do, J.; Jacobson, A.J. Mesostructured lamellar phases containing six-membered vanadium borophosphate cluster anions. Chem. Mater. 2001, 13, 2436-2440. [CrossRef] 
38. Zhang, G.; Ke, H.; He, T.; Xiao, D.; Chen, Z.; Yang, W.; Yao, J. Synthesis and characterization of new layered polyoxometallates-1,10-decanediamine intercalative nanocomposites. J. Mater. Res. 2004, 19, 496-500. [CrossRef]

39. Landsmann, S.; Lizandara-Pueyo, C.; Polarz, S. A new class of surfactants with multinuclear, inorganic head groups. J. Am. Chem. Soc. 2010, 132, 5315-5321. [CrossRef] [PubMed]

40. Watfa, N.; Floquet, S.; Terazzi, E.; Haouas, M.; Salomon, W.; Korenev, V.S.; Taulelle, F.; Guénée, L.; Hijazi, A.; Naoufal, D.; et al. Synthesis, characterization, and tuning of the liquid crystal properties of ionic materials based on the cyclic polyoxothiometalate $\left[\left\{\mathrm{Mo}_{4} \mathrm{O}_{4} \mathrm{~S}_{4}\left(\mathrm{H}_{2} \mathrm{O}\right)_{3}(\mathrm{OH})_{2}\right\}_{2}\left(\mathrm{P}_{8} \mathrm{~W}_{48} \mathrm{O}_{184}\right)\right]^{36-}$. Soft Matter 2015, 11, 1087-1099. [CrossRef] [PubMed]

41. Janauer, G.G.; Dobley, A.D.; Zavalij, P.Y.; Whittingham, M.S. Evidence for decavanadate clusters in the lamellar surfactant ion phase. Chem. Mater. 1997, 9, 647-649. [CrossRef]

42. Spahr, M.E.; Nesper, R. Anhydrous octamolybdate with trimethyl hexadecyl ammonium cations. Z. Anorg. Allg. Chem. 2001, 627, 2133-2138. [CrossRef]

43. Ito, T. Inorganic-organic hybrid surfactant crystals: Structural aspects and functions. Crystals 2016, 6, 24. [CrossRef]

44. Ito, T.; Sawada, K.; Yamase, T. Crystal structure of bis(dimethyldioctadecylammonium) hexamolybdate: A molecular model of Langmuir-Blodgett films. Chem. Lett. 2003, 32, 938-939. [CrossRef]

45. Ito, T.; Ide, R.; Kosaka, K.; Hasegawa, S.; Mikurube, K.; Taira, M.; Naruke, H.; Koguchi, S. Polyoxomolybdate-surfactant layered crystals derived from long-tailed alkylamine and ionic-liquid. Chem. Lett. 2013, 42, 1400-1402. [CrossRef]

46. Ito, T.; Mikurube, K.; Hasegawa, K.; Matsumoto, T.; Kosaka, K.; Naruke, H.; Koguchi, S. Structural variation in polyoxomolybdate hybrid crystals comprising ionic-liquid surfactants. Crystals 2014, 4, 42-52. [CrossRef]

47. Ito, T.; Nakagawa, M.; Kobayashi, J.; Matsumoto, T.; Otobe, S.; Naruke, H. Layered and molecular-structural control in polyoxomolybdate hybrid crystals by surfactant chain length. J. Mol. Struct. 2016, 1106, 220-226. [CrossRef]

48. Ito, T.; Taira, M.; Fukumoto, K.; Yamamoto, K.; Naruke, H.; Tomita, K. Polyoxovanadate-surfactant hybrid layered crystal containing one-dimensional hydrogen-bonded cluster chain. Bull. Chem. Soc. Jpn. 2012, 85, 1222-1224. [CrossRef]

49. Ito, T.; Fujimoto, N.; Uchida, S.; Iijima, J.; Naruke, H.; Mizuno, N. Polyoxotungstate-surfactant layered crystal toward conductive inorganic-organic hybrid. Crystals 2012, 2, 362-373. [CrossRef]

50. Nyman, M.; Ingersoll, D.; Singh, S.; Bonhomme, F.; Alam, T.M.; Brinker, C.J.; Rodriguez, M.A. Comparative study of inorganic cluster-surfactant arrays. Chem. Mater. 2005, 17, 2885-2895. [CrossRef]

51. Nyman, M.; Rodriguez, M.A.; Anderson, T.M.; Ingersoll, D. Two structures toward understanding evolution from surfactant-polyoxometalate lamellae to surfactant-encapsulated polyoxometalates. Cryst. Growth Des. 2009, 9, 3590-3597. [CrossRef]

52. Du, H.-J.; Mi, L.-W.; Yue, Z.-C.; Niu, Y.-Y.; Hou, H.-W. Templated fabrication, isomer recognition of series of 1,10-(alkane-1, $\omega$-diyl)-bis(3-methylimidazolium)-induced polyoxometalates $(\omega=1-11)$. Inorg. Chim. Acta 2014, 409, 418-426. [CrossRef]

53. Yue, Z.-C.; Du, H.-J.; Li, L.; Zhang, W.-L.; Niu, Y.-Y.; Hou, H.-W. Construction and isomer recognition of polyoxometalates functionalized by 1,2-dimethylimidazole alkane templates. Inorg. Chim. Acta 2014, 410, 136-143. [CrossRef]

54. Jiang, Y.; Liu, S.; Li, S.; Miao, J.; Zhang, J.; Wu, L. Anisotropic ionic liquids built from nonmesogenic cation surfactants and Keggin-type polyoxoanions. Chem. Commun. 2011, 47, 10287-10289. [CrossRef] [PubMed]

55. Yin, P.; Wu, P.; Xiao, Z.; Li, D.; Bitterlich, E.; Zhang, J.; Cheng, P.; Vezenov, D.V.; Liu, T.; Wei, Y. A double-tailed fluorescent surfactant with a hexavanadate cluster as the head group. Angew. Chem. Int. Ed. 2011, 50, 2521-2525. [CrossRef] [PubMed]

56. Yin, P.; Bayaguud, A.; Cheng, P.; Haso, F.; Hu, L.; Wang, J.; Vezenov, D.; Winans, R.E.; Hao, J.; Tao, L.; et al. Spontaneous stepwise self-assembly of a polyoxometalate-organic hybrid into catalytically active one-dimensional anisotropic structures. Chem. Eur. J. 2014, 20, 9589-9595. [CrossRef] [PubMed]

57. Zhu, L.; Chen, K.; Hao, J.; Wei, Z.; Zhang, H.; Yin, P.; Wei, Y. Synthesis and crystallization behavior of surfactants with hexamolybdate as the polar headgroup. Inorg. Chem. 2015, 54, 6075-6077. [CrossRef] [PubMed] 
58. Himeno, S.; Niiya, H.; Ueda, T. Raman studies on the identification of isopolymolybdates in aqueous solution. Bull. Chem. Soc. Jpn. 1997, 70, 631-637. [CrossRef]

59. Cruywagen, J.J. Protonation, oligomerization, and condensation reactions of vanadate(V), molybdate(VI), and tungstate(VI). Adv. Inorg. Chem. 1999, 49, 127-182.

60. Klemperer, W.G.; Shum, W. Synthesis and interconversion of the isomeric $\alpha$ - and $\beta-\mathrm{Mo}_{8} \mathrm{O}_{26}{ }^{4-}$ ions. J. Am. Chem. Soc. 1976, 98, 8291-8293. [CrossRef]

61. Desiraju, G.R.; Steiner, T. The Weak Hydrogen Bond in Structural Chemistry and Biology; Oxford University Press: New York, NY, USA, 1999; pp. 12-16.

62. The values of $\mathrm{C} \cdots \mathrm{O}$ distances were measured for $\mathrm{C}-\mathrm{H} \cdots \mathrm{O}$ bonds with $90-180^{\circ}$ of $\mathrm{C}-\mathrm{H} \cdots \mathrm{O}$ angle, which can list more $\mathrm{C}-\mathrm{H} \cdots \mathrm{O}$ bonds to consider weak interactions. The values for $\mathrm{C}_{12} \mathrm{mim}-\beta-\mathrm{Mo}_{8}$ (3) in the literature [45] were estimated based on the $\mathrm{C}-\mathrm{H} \cdots$ O bonds with smaller range $\left(150-180^{\circ}\right)$ of $\mathrm{C}-\mathrm{H} \cdots \mathrm{O}$ angle.

63. Aupoix, A.; Pégot, B.; Vo-Thanh, G. Synthesis of imidazolium and pyridinium-based ionic liquids and application of 1-alkyl-3-methylimidazolium salts as pre-catalysts for the benzoin condensation using solvent-free and microwave activation. Tetrahedron 2010, 66, 1352-1356. [CrossRef]

64. CrystalClear; Rigaku Corporation: Tokyo, Japan, 2014.

65. Sheldrick, G.M. SHELXS Version 2013/1: A short history of SHELX. Acta Cryst. 2008, A64, 112-122. [CrossRef] [PubMed]

66. Sheldrick, G.M. SHELXL Version 2014/7: A short history of SHELX. Acta Cryst. 2008, A64, 112-122. [CrossRef] [PubMed]

67. CrystalStructure 4.1.1; Rigaku Corporation: Tokyo, Japan, 2015.

(C) 2016 by the authors; licensee MDPI, Basel, Switzerland. This article is an open access article distributed under the terms and conditions of the Creative Commons Attribution (CC-BY) license (http:/ / creativecommons.org/licenses/by/4.0/). 